- Dentists and dental care professionals should identify domestic violence

- Dentists and dental care professionals should provide information about where the patient who is experiencing domestic violence may get help

- The UK Department of Health has provided guidance for healthcare professionals including dental professionals about dealing with domestic violence

\title{
The role of the dental team in responding to domestic violence
}

\author{
P. Coulthard ${ }^{1}$ and A. L. Warburton ${ }^{2}$
}

\begin{abstract}
The face is a common target in assault and consequently the dentist and dental care professional has a part to play in identifying domestic violence. ${ }^{1,2}$ Domestic violence is a term which refers to a wide range of physical, sexual, emotional and financial abuse of people who are, or have been, intimate partners - whether or not they are married or cohabiting. ${ }^{3,4}$ Although domestic violence can take place in any intimate relationship, including gay and lesbian partnerships, and whilst abuse of men by female partners does occur, the great majority and the most severe incidents of domestic violence, are perpetrated by men against women and we have therefore elected refer to the victim of assault in this paper as 'she' for ease of writing.
\end{abstract}

The dental professional's role in domestic violence has expanded in recent years to include adults in addition to its recognition in children. ${ }^{5}$ It is however not the job of the dentist or dental care professional to give advice to someone experiencing domestic violence on what direct action they should take. We know that if, for example, a women is encouraged to leave her partner then she may be at greater risk of harm. The role of the dental team is to identify domestic violence and provide information about where the individual can go for help. Some dentists and dental care professionals may not consider that this is their responsibility

\footnotetext{
${ }^{1 *}$ Professor, Oral and Maxillofacial Surgery, The School of Dentistry, The University of Manchester, Higher Cambridge Street, Manchester M15 6FH; ${ }^{2}$ Centre for Women's Mental Health Research, Division of Psychiatry, Williamson Building, University of Manchester, Manchester, M13 9PL

${ }^{*}$ Correspondence to: Professor Paul Coulthard

Email: paul.coulthard@manchester.ac.uk
}

\section{Refereed Paper}

Accepted 20 March 2007

DOI: $10.1038 /$ bdj.2007.1066

${ }^{\circ}$ British Dental Journal 2007; 203: 645-648 because they assume that social services or the police will be doing something. ${ }^{6}$ However, other services may not have been approached by the individual. It is useful to take advantage of working in the dental environment, which is likely to be considered less stigmatising than some other statutory services, to create an opportunity for the patient to reveal domestic violence and ask for help. Some dentists may think that this role is more appropriate for the medical practitioner rather than themselves but physicians receive minimal training in oral health and dental injury and may not detect dental aspects of abuse. ${ }^{7}$

The UK Department of Health offers guidance for healthcare professionals, including dentists, on how to respond to domestic violence. A manual, Domestic violence: a resource manual for healthcare professionals published in $2000^{8}$ was more recently superseded by Responding to domestic abuse: a handbook for health professionals. ${ }^{9}$ The handbook is designed to offer practical guidance for those working with patients who are experiencing domestic violence. Some healthcare professionals have of course always been offering support to their patients irrespective of these publications but the handbooks are designed to encourage all healthcare professionals to adopt the same approach to ensure that the same standard of response is available to those experiencing domestic violence.

\section{THE DENTAL ENVIRONMENT}

The presence of a partner or a relative may constrain discussion of domestic violence because, regrettably, the perpetrator may be a carer and discussion could place the woman in greater danger. Discussion should not take place in the presence of children. Due to the nature of dentistry, patients are often unaccompanied during examination and treatment sessions as part of routine practice, and therefore dental staff are in a unique position to undertake enquiry about domestic violence. It may be possible to divert the partner to the reception for the completion of 
documentation, so as to see a patient on their own without arousing suspicion. It is important that all members of the dental team are aware of the issues around domestic violence screening and therefore facilitate the process. For example, a women experiencing domestic violence may phone the practice to request an emergency appointment without wishing to provide any information about the need for the appointment. Reception staff are 'frontline' and would need to understand that this is acceptable and not attempt to obtain details that the patient is reluctant to provide.

\section{Asking about domestic violence}

It is not easy to ask, or for a patient to be asked, about domestic violence but the health professional should be proactive. If the dentist and team only focus on treating injuries, without asking about their cause, then they will be doing little to help the patient experiencing domestic violence. If there are signs suggesting that a patient may be experiencing domestic violence, then the dentist or dental care professional should ask direct and specific questions. Vague enquiries are not helpful. Likely indicators of domestic violence which should arouse suspicion are listed in Table 1 , although one should always be aware that there is a wide range of reaction to domestic violence. ${ }^{9}$ While some patients may appear withdrawn or depressed, others may be agitated and angry. Similarly, perpetrators of domestic violence will not necessarily fit stereotypes, and while some will be overtly aggressive and domineering, others may appear concerned, charming and attentive.

\section{Routine enquiry}

An alternative approach is to ask all women about domestic violence rather than rely on signs observed in patients presenting with physical injury. All NHS Trusts in the UK are being encouraged by the Department of Health to adopt this 'routine enquiry' approach and to provide the necessary staff training. Training is acknowledged to be essential before embarking on routine enquiry. Questioning by untrained staff, however wellintentioned, can be damaging and leave a woman vulnerable to further violence. There has been some debate about the appropriateness of introducing routine

\section{Some facts}

- $23 \%$ of women and $15 \%$ of adult men report having been physically assaulted by a partner at some time in their lives ${ }^{21}$

- Every week in the UK two women are killed by current or former partners 3,22

- Domestic violence accounts for $16 \%$ of all violent crime ${ }^{3}$

- On average a woman will be assaulted by her partner or ex-partner 35 times before reporting it to the police ${ }^{23}$

- Violence can begin or intensify following separation from an abusive partner ${ }^{4}$

- Domestic violence occurs at similar prevalence among people at all income levels, and among people from all white, black and minority ethnic backgrounds. ${ }^{4}$

Diagram showing principles of practice for enquiring about domestic violence and referral to appropriate agencies. Adapted from Responding to domestic abuse: a handbook for health professionals ${ }^{9}$

- Help create an environment that will facilitate disclosure of domestic violence

- Be aware of signs that could indicate a patient is experiencing domestic violence

- Know how to ask the right questions to let a patient know that she can talk about domestic violence. Explain the limits of confidentiality

- Validate and support patients who do not reveal domestic violence

- Be aware of support services and have written information available to pass to patients

- Provide the patient information whether or not she reveals domestic violence

- Keep accurate and detailed records of any injuries and information revealed

- Ensure confidentiality

- Treat physical dental injuries as appropriate.

enquiry in healthcare settings other than ante-natal care. The arguments against routine questioning typically identify the time constraints in clinical practice, which create barriers to implementation. However, a review of approaches to asking women about domestic violence in healthcare settings concluded that universal screening rather than by selective screening based on risk factors is likely to be superior in identification of domestic violence. ${ }^{10}$ As screening for domestic violence by healthcare professionals is still in its infancy there is not yet a lot of high level evidence to confirm the benefits for patients. ${ }^{11}$

When undertaking routine enquiry the dental professional should be confident and supportive in their approach, expressing concern as necessary but without accusation or being patronising.
The appropriate time to ask is probably as part of taking the social history. Later, when examining the patient, if the injuries do not appear to be consistent with the stated aetiology, then the dental professional should explain this concern to the patient.

The patient may be fearful of talking about her own experience, particularly if the abuse has been taking place over a long period of time and has led to low self-esteem. Women who experience domestic violence often try to explain it to themselves, and others, by seeing it as their responsibility or fault, and the response of others to their situation may have reinforced this view. Before asking direct questions, the dental professional should begin with some indirect ones to help in establishing a relationship with the patient and developing empathy. ${ }^{12}$ 
Table 1 Some likely indicators of domestic violence ${ }^{10}$

- Frequent appointments for vague complaints or symptoms

- Frequent missed appointments

- Partner always attends unnecessarily

- Injuries inconsistent with explanation of cause

- Multiple injuries at different stages of healing

- Woman tries to hide or minimise injuries

Patient appears frightened, overly anxious or depressed

- Women is submissive or afraid or reluctant to speak in front of her partner

- Partner is aggressive or dominant, talks for a women or refuses to leave the room

Non-compliance with treatment.

\section{Useful contacts}

National helplines

Freephone 24-hour National Domestic Violence Helpline

Helpline 08082000247

Web www.womensaid.org.uk/

www.refuge.org.uk

Wales Domestic Abuse Helpline

Helpline 08088010800

Web www.welshwomensaid.org

Scottish Domestic Abuse Helpline

Helpline 08000721234

Web www.scottishwomensaid.co.uk

Northern Ireland Women's Aid 24-hour Domestic Violence Helpline

Helpline 08009171414

Web www.niwaf.org

Examples include: 'Is everything alright at home?' or 'Are you being looked after properly/is your partner taking care of you?', and 'Are you ever afraid at home?'.

It may be helpful to explain why the questions are being asked by explaining, 'I am sorry if someone has already asked you about this, and I don't wish to cause you any offence, but we know that throughout the country one in four women experiences violence at home at some time during their life and so we are asking all women about this issue.' More direct questions may include: 'Have you ever been in a relationship where you have been hit or hurt in some way?', 'Are you currently in a relationship where this is happening to you?', 'Has your partner ever destroyed or broken things you care about?', 'Has your partner ever threatened or hurt your children?', and 'Does your partner get jealous of you seeing friends, talking to other people or going out? If so, what happens?' If responding to dentofacial injury then it may be helpful to suggest, 'Your partner seems very concerned and anxious about you. Sometimes people react like that when they feel guilty, was he responsible for your injuries?'.

\section{Respect and validation}

All healthcare professionals must recognise that their response to a woman experiencing domestic violence is of great importance. It may have taken a woman many months or years to reach the point at which she is able to disclose her abuse. How she is treated will be significant in determining whether she is able to disclose more and seek help, or whether she mistrusts professionals and is left to face continued violence alone. When a disclosure has been made, it is essential that the response of health professionals is sympathetic, supportive and non-judgemental. ${ }^{13}$ It is important to emphasise the fact that confidentiality will be maintained. Central to a position of respect and validation must be support to a woman in whatever decisions she makes. This will include avoidance of criticism of women who choose to remain with an abusive partner. There may be many reasons why such a decision is made.

\section{Referral}

The purpose of identification of domestic violence is referral on to the appropriate agency and so this process must be considered prior to starting screening. The referral to agencies providing direct help may be made by providing leaflets and cards with contact details to take away. Many agencies supply cards that are small enough to be hidden by the patient, for example, in a shoe so that the partner is unaware. Displaying posters in the waiting room with a contact telephone is also useful and provides a signal to encourage patients to disclose their domestic violence experience. The dentist or member of the team may wish to also help by offering to help make contact with other agencies on behalf of the women. Written information should be available in a range of languages that are appropriate for the local area.

Specialist agencies provide help by supporting women to: make sense of the violence and abuse they are experiencing; develop safety plans and assess the risks to both themselves and their children; be able to consider all of their available options; to advocate on their behalf with other agencies; help them develop coping strategies and to help them leave an abusive relationship.

\section{Record keeping}

Documentation and record keeping have an important role in responding to domestic violence. The British Medical Association has stressed the need for evidence, particularly in the event of the perpetrator of violence being charged with assault. Evidence can also be important in helping an abused woman to obtain protection through an injunction or court order, in opposing an immigration or deportation case, and can be used by the family courts to 
assess possible risks in granting access to children to a violent parent.

Extreme care needs to be taken with documenting domestic violence. In order to maintain confidentiality, any record of domestic violence should be kept separately from notes which may be held by the patient or which the perpetrator could have access to. Confidentiality should be discussed with the patient and their consent should be obtained if information needs to be shared with other healthcare professionals, or with other agencies.

The physical safety of victims of domestic violence can be dependent on confidentiality being maintained. However, all healthcare workers must understand, and be honest about, the limits to confidentiality. When there are reasons to believe that the patients children are at risk, then protection of the children must take precedence over patient confidentiality, and Child Protection Guidelines and protocols must be followed.

\section{Training for dentists and} dental care professionals

The UK National Domestic Violence Training Forum has identified three training level requirements:

1) Core training for health professionals

2) Additional training for health pro-

fessionals with specialist responsi-

bilities regards domestic abuse or case responsibility

3) In depth training for professionals with a therapeutic specialism, clinical supervisors or managers.

The US has adopted similar principles for training. ${ }^{14}$ The appropriate level of training for dentists and dental care professionals should be core training. Ideally core training should begin as an undergraduate. ${ }^{15}$

If training is not provided than dentists are likely to feel unprepared to undertake their role with confidence in domestic violence screening and referral. This has been observed in dentists regarding the child protection process. ${ }^{16}$ Similarly when a group of Australian dental professionals were assessed on their level of knowledge and attitude towards their role in child abuse were found to have a high level of interest but in need of further information and training. ${ }^{17}$

The authors have previously demonstrated that even a brief domestic violence training intervention such a lecture can be effective in raising awareness, increasing knowledge and changing attitudes of dentists and their team. ${ }^{18}$ However it was recognised that this intervention could lead to false confidence in staff and should be followed by in depth practical training. Knowledge about domestic violence and its relevance to dental practice were significantly improved. Before the awareness raising lecture, only 5\% correctly thought that patients didn't mind being asked about domestic violence, compared with $63 \%$ post-training. A recent randomised control trial in the US also investigated the effectiveness of a brief intervention designed to educate dentists in identifying and responding to domestic violence. ${ }^{19}$ These authors developed an interactive multimedia tutorial and concluded that it was effective in helping dentists learn how to identify and help patients who are experiencing abuse.

\section{SUMMARY}

Dentists and dental care professionals should be confident in the identification of domestic violence when a patient presents with dental or facial injury. They should be prepared to refer the patient to the appropriate agencies that can offer direct help and therefore have printed literature available, especially in the form of small cards, in readiness to provide for patients. Dentists and dental care professionals could also consider routine enquiry after appropriate training. The UK National Domestic Violence Training Forum have recommended that training become incorporated into mandatory induction procedures when individuals take up posts in the NHS and then receive on going training as par of continuing professional education.
1. Le B T, Dierks E J, Ueeck B A, Homer L D, Potter B F. Maxillofacial injuries associated with domestic violence. Br J Oral Maxillofac Surg 2001; 59: 1277-1283.

2. Gilthorpe M S, Wilson R C, Moles D R, Bedi R. Variations in admissions to hospitals for head injury and assault to the head Part 1: age and gender. Br J Oral Maxillofac Surg 1999; 37: 300.

3. Home Office. The 1998 British Crime Survey: England and Wales, 1998.

4. Walby S, Allen J. Home Office research study 276. Domestic violence, sexual assault and stalking: findings from the British Crime Survey. 2004.

5. Kenney J P. Domestic violence: a complex healthcare issue for dentistry today. Forensic Sci Int 2006; 159 Suppl 1: S121-S125.

6. Senn D R, McDowell J D, Alder M E. Dentistry's role in the recognition and reporting of domestic violence, abuse, and neglect. Dent Clin North Am 2001; 45: 343-363.

7. Kellogg N, American Academy of Pediatrics Committee on Child Abuse and Neglect. Oral and dental aspects of child abuse and neglect. Pediatrics 2005; 116: 1565-1568.

8. Department of Health. Domestic violence: a resource manual for healthcare professionals. 2000.

9. Department of Health. Responding to domestic violence: a handbook for health professionals. 2005.

10. Ramsay J, Richardson J, Carter Y H, Davidson L $L$, Feder G. Should health professionals screen women for domestic violence? Systematic review. BrMed J 2002: 325: 1-13.

11. Coulthard P, Yong Sin, Esposito M et al. Domestic violence screening and intervention programmes for adults with dental or facial injury. The Cochrane Database of Systematic Reviews 2004, Issue 2. Chichester, UK: John Wiley \& Sons, Ltd., 2004

12. British Medical Association. Advice on good practice for identifying and dealing with domestic violence. 1998.

13. Feder G S, Hutson M, Ramsay J, Taket A R. Women exposed to intimate partner violence: expectations and experiences when they encounter healthcare professionals: a meta-analysis of qualitative studies. Arch Intern Med 2006; 9; 166: 22-37.

14. Brandt E N Jr. Curricular principles for health professions education about family violence. Acad Med 1997; 72: S51-S58.

15. Department of Health, Social Services Inspectorate. Domestic violence and social care: a report on two conferences held by the SSI. p 37. 1995

16. Welbury R R, MacAskill S G, Murphy J M et al. General dental practitioners' perception of their role within child protection: a qualitative study. Eur J Paediatr Dent 2003; 4: 89-95.

17. John V, Messer L B, Arora R et al. Child abuse and dentistry: a study of knowledge and attitudes among dentists in Victoria, Australia. Aust Dent J 1999; 44: 259-267.

18. Warburton A L, Hanif B, Rowsell C, Coulthard P. Changes in the levels of knowledge and attitudes of dental hospital staff about domestic violence following attendance at an awareness raising seminar. Br Dent J 2006; 201: 653-659.

19. Hsieh N K, Herzig K, Gansky S A, Danley D, Gerbert B. Changing dentists' knowledge, attitudes and behavior regarding domestic violence through an interactive multimedia tutorial. J Am Dent Assoc 2006; 137: 596-603. 